\title{
ACUMULAÇÃO FLEXÍVEL: DO LOCAL AO GLOBAL, DO OBSOLETO AO MODERNO
}

\author{
Roney Gusmão do Carmo ${ }^{1}$
}

\section{RESUMO}

As mudanças sinalizadas pela acumulação flexível impactaram diversas esferas da sociedade em diferentes lócus ao redor do mundo. Embora o capitalismo flexível tenha uma conotação basicamente econômica, sua atuação atingiu a subjetividade dos sujeitos, reorganizou os espaços urbanos e impôs novas condições que atingiram radicalmente a relação dialética entre o "local" e o "global". De todo modo, falar de acumulação flexível, é falar de uma etapa histórica do capitalismo, o que implica em considerar as novas estratégias de perpetuação do capital num contexto de transitoriedade política e social. Palavras-chave: acumulação flexível, desigualdade, dialética, capitalismo.

\section{FLEXIBLE ACCUMULATION: FROM THE LOCAL TO GLOBAL, FROM THE OBSOLETE TO THE MODERN}

\section{ABSTRACT}

The changes signaled by flexible accumulation impacted various spheres of society at different spaces around the world. Although flexible capitalism has a connotation basically economic, its performance has reached the subjectivity of the subject, reorganized the cities and imposed new conditions that have reached radically dialectical relationship between "local" and "global". Anyway, speaking of flexible accumulation, is talking about a historical stage of capitalism, which involves considering new strategies for the perpetuation of the capital in a context of political and social transience.

Keywords: flexible accumulation, inequality, dialectics, capitalism.

\section{ACUMULACIÓN FLEXIBLE: DEL LOCAL A L GLOBAL, DEL MODERNO AL OBSOLETO}

\section{RESUMEN:}

Los cambios señalados por la acumulación flexible afectan diversos ámbitos de la sociedad en diferentes loci en todo el mundo. Aunque el capitalismo flexible tiene una connotación económica en gran parte, su rendimiento ha llegado a la subjetividad de los sujetos, reorganizando los espacios urbanos e impondo nuevas condiciones que alcanzaron radicalmente la relación dialéctica entre "local" y "global". De todos modos, hablando de la acumulación flexible, es hablar de una etapa histórica del capitalismo, que consiste en considerar nuevas estrategias para la perpetuación del capital en un contexto de transitoriedad política y social.

Palabras clave: acumulación flexible, la desigualdad, la dialéctica, el capitalismo. 


\section{Introdução}

Atualmente estamos desenvolvendo estudos em torno dos impactos da reestruturação produtiva no município de Vitória da Conquista (Bahia) nesses últimos anos. Embora as transformações locais aparentemente demonstrem-se advindas de uma dinâmica interna à cidade, entendemos que tal perspectiva negligencia a grandiosidade do que o sistema capitalista tem vivenciado nesse início de séculos. Com quase simultaneidade, a cidade de porte médio a qual nos referimos, recebeu uma quantidade significativa de empreendimentos advindos do capital externo, são hipermercados, shopping-centers, lojas de departamentos, redes de fast-foods que geraram uma sensação metropolitana à cidade.

Essas transformações se tornaram pretexto político de campanhas partidárias que sempre salientaram o teor vigorante da aparente sensação de prosperidade nesses últimos anos, fato que atingiu profundamente o imaginário popular e as representações esboçadas pelos discursos dos sujeitos acerca do superficial cosmopolitismo local. Na ótica do senso comum, Vitória da Conquista hoje é "cidade grande", cujo espaço tem sido trincado por logomarcas, mega-empreendimentos e condutas voltadas a um consumismo esvaziado de sentido, porém sincronizado às tendências do "mundo moderno".

Se por um lado, a dinâmica econômica local tem gerado uma consensual percepção de que a cidade tem prosperado, por outro os efeitos perniciosos dessas mudanças só são percebidas quando se excede a aparência e se adentra a realidade de exclusão que coexiste com a ascensão econômica. Embora, os grandes empreendimentos comerciais tenham alterado o espaço e as relações de trabalho locais, tal processo mascara a contradição e encobre a exclusão advinda das condições impostas pela atual fase do capitalismo.

Assim, para além das aparências, esse texto pretende esquadrinhar os efeitos da acumulação flexível no cenário local, salientando o lócus em análise como parte de uma totalidade dialética, inscrita numa história em curso, cuja análise solicita considerar a amplitude dos metabolismos sinalizados pelo capital no decorrer dos últimos séculos.

De todo modo, foi empenho desta análise adentrar o campo da cotidianidade com vistas a interpretar as representações comuns elaboradas por homens e mulheres acerca do fenômeno tratado. Assim, foram aplicados cinquenta questionários a trabalhadores do comércio local, além de entrevistas semi-estruturadas, a vinte destes trabalhadores comerciários e outras entrevistas livres a quinze dos comerciantes da cidade. O objetivo foi entender a forma como sujeitos, situados em distintos lócus e condições econômicas, visualizam as transformações e reconstroem suas trajetórias de vida como mecanismo de interpretação das mudanças históricas nítidas na cidade.

Ademais, é interessante observar que a intencional variação de idade e forma de inserção no mercado entre os entrevistados se tornou pertinente na presente análise, pois permitiu concluir que interpretações às mudanças nítidas no cenário local ocorrem a partir de experiências diluídas em trajetórias pessoais de vida. Logo, pensar em mudanças, e tentar entendê-las a partir da vida cotidiana, implica em reconhecer que as leituras são muitas e demasiadamente associadas às condições concretas de existência social que participam ativamente das subjetivações esboçadas nos discursos dos sujeitos.

Também é útil acrescentar que a dialética do senso comum - bastante discorrida por Kosik (2010) quando aborda o conceito da pseudoconcreticidade - é substância significativa do presente texto, uma vez que entendemos as representações mais ordinárias, elaboradas no dia a dia, como matéria inscrita numa totalidade cambiante e imbricada num todo temporo-espacial. Desse modo, a presente abordagem valoriza o campo cotidiano de existência, bem como os discursos dele suscitados, todos imbricados em um dinamismo 
dialético, que metamorfoseia a estrutura social e, por efeito, a experiência de homens comuns dentro de temporalidades específicas.

\section{Acumulação flexível: conceito, contexto e contradições}

Extraímos o termo "acumulação flexível" da obra de Harvey (1993), que entende tal fenômeno como uma contraposição ao processo produtivo vigente até meados do século XX. É interessante ressaltar que o modelo taylorista/fordista vigorante na primeira metade do século XX, embora não tenha aportado tão visivelmente no Brasil, se calcava numa produção de mercadorias estandardizadas produzidas em larga escala com vistas à estocagem. As grandes fábricas fordistas, traçadas por linhas de montagem se demonstraram pedadas e rígidas demais para o contexto histórico vigorante em meados do século XX, uma vez que as inconstâncias do sistema, oscilante pelas sequentes crises, solicitavam um sistema flexível e, portanto, organizado por uma gestão preparada a diferentes condições de crescimento e encolhimento do sistema econômico. Concordamos com Harvey (1993), quando afirma que o fordismo se mostrava oportuno num cenário de crescimento econômico, rígido demais para suportar adversidades econômicas; ao passo que a acumulação flexível se adequa a um cenário de incertezas e volatilidade, insinuando um modelo produtivo sincronizado à efemeridade do mercado.

O que é singular na incerteza hoje é que ela existe sem qualquer desastre histórico iminente; ao contrário, está entremeada nas práticas cotidianas de um vigoroso capitalismo. A instabilidade pretende ser normal, o empresário de Schumpeter aparecendo como o Homem Comum ideal. Talvez a corrosão de caracteres seja uma consequência inevitável. "Não há mais longo prazo" desorienta a ação a longo prazo, afrouxa os laços de confiança e compromisso e divorcia a vontade do comportamento (SENNET, 2009, p. 33).

É, portanto, nesse contexto de incertezas oscilantes do sistema econômico global, que nasce paulatinamente a acumulação flexível. Trata-se de uma mudança de gestão e perspectivas internas à empresa, porém, mais que isso, refere-se ao avassalador processo de desterritorialização com busca voraz por novos nichos do mercado consumidor, com maximização da concorrência e remodelagem da arena predatória de consumo global. No contexto de acumulação flexível, países em desenvolvimento, como o Brasil, receberam um contingente imenso de transnacionais, fenômeno apoiado por uma política neoliberal absolutamente complacente com a atual dinâmica do capital (HARVEY, 1993).

Nesse cenário, as metas dos governos brasileiros no período de transição entre séculos XX e XXI, foram marcadas pela liberação econômica e realçadas por estratégias de favorecimento às condições de lucratividade das transnacionais. As condições de lucratividade em território brasileiro se tornaram tão propícias, que as empresas aportaram aqui numa atuação cada vez mais predatória, contando com flexibilização de leis trabalhistas, supressão de sindicatos, isenção fiscal e demolição da concorrência com micro-empreendimentos. As fusões e formações de grandes conglomerados resultaram numa acumulação de capitais que lhes permitiram investir amplamente em marketing e na remodelagem de suas franquias, que houve polarização extremada do mercado consumidor.

O contexto atual, marcado por um capitalismo flexível, se caracteriza pela ampliação dos mercados, especialmente com a transnacionalização do capital e por uma avassaladora polarização do consumo efetuado por mega-empreendimentos que têm 
atingido diversos espaços do planeta. $\mathrm{O}$ formato de gestão, alicerçada na minimização dos custos produtivos, se tornou então mais eficiente para as inconstâncias do mercado e para os momentos de desaquecimento da economia, fazendo, então, da flexibilidade um princípio de sobrevivência empreendedora no contexto atual.

Evidentemente, a acumulação flexível não corresponde apenas a uma adequação dos modelos de gestão equalizados às demandas atuais; trata-se, sobretudo, de uma remodelagem na subjetividade intrínseca à prática social cotidiana de homens e mulheres presentes nesse contexto. A necessidade de fomento ao consumo, associado à sofisticação da era técnico-científica e informacional, tem atingido as relações sociais, afetando o mais profundo das emoções, sonhos, fantasias, desejos e ambições dos seres humanos. Assim, a obsessão pela compra, a obsolescência das mercadorias, bem como o fetichismo exercido pela propriedade tem acarretado num endividamento sufocante e numa busca desenfreada pelo consumo na ilusória tentativa de encontrar na compra a satisfação de todas as demandas mais particulares dos sujeitos. Por efeito, constrói-se uma humanidade agarrada pela sensação fugidia gerada pelo consumo e por um individualismo embrutecedor, com apego visceral à superficialidade do status promovido pela aquisição de coisas, que, nesse contexto, se sobrepõe a valores outros.

A meia vida de um produto fordista típico, por exemplo, era de cinco a sete anos, mas a acumulação flexível diminuiu isso em mais da metade em certos setores [...] A acumulação flexível foi acompanhada na ponta do consumo, portanto, por uma atenção muito maior às modas fugazes e pela mobilização de todos os artifícios de indução de necessidades e de transformação cultural que isso implica. A estética relativamente estável do modernismo fordista cedeu lugar a todo o fermento, instabilidade e qualidades fugidias de uma estética pós-moderna que celebra a diferença, a efemeridade, o espetáculo, a moda e a mercadificação de formas culturais (HARVEY, 1993, p. 148).

A dissolução de ideias agregadas ao coletivismo se torna tamanha que, inclusive, os trabalhadores serão atingidos em sua subjetividade por novos paradigmas individualizantes. Ainda no início do século XX, os grandes e desconfortáveis galpões das montadoras de veículos nos países desenvolvidos possuíam grandes contingentes de trabalhadores que estabeleciam entre si relações sociais e profissionais, marcadas por um inevitável senso de identidade que os unia. A condição de explorados os conectava, ao ponto de gerar a percepção de que se convivia cotidianamente com problemas econômicos semelhantes, demandas sociais semelhantes que, por efeito, fizeram brotar reinvindicações semelhantes. Nessa situação, os trabalhadores foram se articulando, atingindo níveis elevados de organização sindical e recebendo direitos trabalhistas consideráveis. No Brasil, somente a década de 1980 apresentou refrações desse contexto de lutas, com marcantes movimentos sociais que tomaram as ruas, bem como conquistas sindicais significativas que, inevitavelmente fortaleceram o senso de coletividade entre os trabalhadores.

Com o advento da produção flexível e de suas inovações técnicogerenciais, com a exemplaridade da fábrica enxuta, a fragmentação crescente da classe trabalhadora, advinda das transformações das relações salariais, com a fragilização do poder de pressão dos sindicatos e a desmobilização visível dos movimentos operários nos últimos trinta anos, fica cada vez mais difícil construir identidades sólidas pela via do trabalho. A situação de instabilidade que caracteriza as novas formas de emprego, surgidas no contexto da flexibilização produtiva e normatizadas 
sob a égide de políticas de inspiração neoliberal, torna as trajetórias profissionais bastante imprevisíveis (BARBOSA, 2011, p. 3).

Entretanto, o final do século XX foi caracterizado pelo desmantelamento do perfil de trabalhador até então existente. A articulação sindical, bem como as conquistas dela advindas, se tornaram por demais onerosas, o que redundou no aumento dos custos de produção e consequentes danos à competitividade num cenário de acirrada disputa por mercados. Barateamento dos custos de produção se tornou, portanto, condição de sobrevivência no contexto de flexibilidade, gerando uma disseminação do modelo japonês de gestão que contribuiu para reorientar as relações de trabalho na atualidade.

Dessa forma, a lógica da individualização da ação inerente à estrutura da empresa neoliberal em rede e financeirizada predomina sobre a lógica da ação coletiva inerente ao sindicalismo. A condição fragmentária [...] produz efeito assíncrono: a multiplicidade de temporalidades, deriva do labor cotidiano, "bloqueia" severamente a ação propriamente coletiva. [...] $\mathrm{E}$ as lutas mais ou menos vinculadas ao reconhecimento da dignidade individual - contra o assédio moral, pelo direito de ir ao banheiro, pela ampliação dos intervalos, pela melhoria dos lanches... - acomodam-se no espaço outrora reservado às lutas salariais do conjunto da categoria (BRAGA, 2009, p. 86).

As ideias de Taichi Ohno se apoiavam no desmembramento da esteira rolante do padrão fordista, sinalizando para a inserção de todos os trabalhadores na totalidade do processo produtivo. Foram criadas ilhas de trabalho, com rotatividade de lideranças e alternância de membros, sendo, então, traçadas metas e incentivos permanentes aos trabalhadores para alcance do que era entendido como "vitória de todos". De modo bastante peculiar, o modelo japonês passou a fazer uso de artifícios para atingir a subjetividade dos trabalhadores, introduzindo comparações metafóricas aos treinamentos, como: "somos a família Toyota" ou também através do uso de contos, parábolas e comparações com práticas esportivas de modo a convencer os funcionários de que esta correspondia a uma gestão solidária, carente da adesão "voluntária" de todos (ALVES, 2011).

O sistema Toyota teve sua origem na necessidade particular em que se encontrava o Japão de produzir pequenas quantidades de numerosos modelos de produtos; em seguida evoluiu para tornar-se um verdadeiro sistema de produção. Dada sua origem, esse sistema é particularmente bom na diversificação. Enquanto o sistema clássico de produção de massa planificado é relativamente refratório à mudança, o sistema Toyota, ao contrário revela-se muito plástico; ele adapta-se bem às condições de diversificação mais difíceis. É porque ele foi concebido para isso (OHNO apud PINTO, 2010, p. 61-62).

O poder coercitivo da ideologia flexível do toyotismo impactou de tal forma a subjetividade de homens e mulheres que qualquer conduta de não adequação e reinvindicação passou a ser considerado rebeldia. Agora, a dimensão humana e psicológica presente nos treinamentos se tornou esvaziada de coletivismo e calcada num individualismo doentio, capaz de mutilar a coletividade sindical de outrora.

A segmentação dos empregos, do mesmo modo que o irresistível 
aumento dos serviços, acarreta uma individualização dos comportamentos no trabalho completamente distinta das regulações coletivas da organização "fordista". Não basta mais saber trabalhar, é preciso saber tanto quanto, vender e se vender. Assim, os indivíduos são levados a definir, eles próprios, sua identidade profissional e a fazer com que seja reconhecida numa interação que mobiliza tanto um capital pessoal quanto uma competência técnica geral (CASTEL, 1998, p. 600).

O trabalho ideológico da acumulação flexível introduzia artifícios psíquicos, imagéticos, discursivos e políticos para capturar a subjetividade dos sujeitos e impor, pelo consentimento, uma prática superficialmente coletivista, mas voltada para a lucratividade máxima dos donos do capital. O aviltamento do trabalho se tornou mascarado por uma sofisticação ideológica dos mecanismos de exploração, agora tidos como "bem comum".

As inovações sociometabólicas do capital se disseminam por meio de treinamentos em empresas, políticas governamentais, currículos escolares, aparatos midiáticos da indústria cultural e, inclusive, igrejas, que constituem uma pletora de "valores expectativas e utopias de mercado" que se cristalizam em noções, vocábulos ou conceitos que falam por nós nas instâncias de produção social. Eles são uma espécie de "nova língua" ou espécie de vulgata do capitalismo neoliberal. É o que Bordieu e Wacquant denominam de "imperialismo simbólico" (ALVES, 2011, p. 90).

Evidentemente, para que este projeto burguês de sociedade flexível ocorresse, o Estado dispôs sua máquina para o capital privado, consentindo com a supressão de direitos e proliferação de relações frágeis de trabalho, intermediando, inclusive, muitas dessas relações de exploração com programas de fomento à contratação. A centralização do capital se tornou, destarte, a máxima desse novo capitalismo flexível, recrudescendo a desigualdade social e disseminando um novo perfil de trabalhador, de cidadão e de ser humano, agora sob o estigma do consumo e da subsunção à ação predatória do capital.

A socialização do trabalhador nas condições capitalistas envolve o controle social bem amplo das capacidades físicas e mentais. A educação, o treinamento, a persuasão, a mobilização de certos sentimentos sociais (a ética do trabalho, a lealdade aos companheiros, o orgulho local ou nacional) e pretensões psicológicas (a busca da identidade através do trabalho, a iniciativa individual ou a solidariedade social) desenham um papel e estão claramente presentes na formação de ideologias dominantes cultivadas pelos meios de comunicação de massa, pelas instituições religiosas e educacionais, pelos vários setores do aparelho do Estado, e afirmadas pela simples articulação de sua experiência por parte dos que fazem trabalho. Também aqui o "modo de regulamentação" se torna uma maneira útil de conceituar o tratamento dados aos problemas da organização da força de trabalho para propósitos de acumulação do capital em épocas e lugares particulares. (HARVEY, 1993, p. 119).

\section{A acumulação flexível numa perspectiva dialética}

A imbricação das partes dentro de uma totalidade dialética á parte fundamental dos caminhos teórico-metodológicos da pesquisa a qual debruçamos. Entendemos que todo microcosmos está inscrito numa dinâmica mais ampla que compõe um todo orgânico, cujas metamorfoses são imprescindíveis para compreensão de fatos locais. Nesse sentido, 
entender as metamorfoses sociais, econômicas ou políticas de um recorte empírico qualquer, recruta investigar os trâmites históricos da totalidade que inferem sentidos à partícula em análise.

Esta recíproca conexão e mediação da parte e do todo significam a um só tempo: os fatos isolados são abstrações, são momentos artificiosamente separados do todo, os quais só quando inseridos no todo correspondem adquirem verdade e concreticidade. Do mesmo modo, o todo de que não foram diferenciados e determinados os momentos é um todo abstrato e vazio. (KOSIK, 2010, p. 49).

Naturalmente, a totalidade dialética a qual nos referimos possui um curso histórico, cujos caminhos são entendidos na conexão entre passado e presente. Por esta constatação, o contexto atual de capitalismo flexível é um fenômeno histórico, em que sua compreensão ocorre mediante análises acerca das diferentes estratégias do capital em subsistir no decorrer dos tempos. Hoje, a acumulação flexível é condição de sobrevivência do capitalismo mediante os desafios postos numa conjuntura de incertezas e num arranjo econômico variante.

Em um sistema burguês desenvolvido, toda relação econômica pressupõe outras relações na forma econômica burguesa e, portanto, todo fato é ao mesmo tempo um pressuposto; assim efetivamente acontece em todo sistema orgânico. Este mesmo sistema orgânico, como totalidade, tem os seus pressupostos, e o seu desenvolvimento no sentido da totalidade consiste justamente no submeter a si todos os elementos da sociedade ou no criar para si os órgãos que ainda lhe faltam. Transforma-se em totalidade histórica. O desenvolvimento rumo a esta totalidade é um momento do seu processo, de seu desenvolvimento. (MARX apud KOSIK, 2010, p. 59).

A volatilidade do capital, associada a uma tecnologia cada vez mais globalizante, gerou uma rede infindável de empresas com unidades produtivas espalhadas pelo mundo. Essas redes gerenciam distintos mercados consumidores, impondo padrões de consumo e remodelando o comportamento das pessoas pela criação de necessidades e fetiches moldados à prioritária ideia de consumo extremado. No interior de países com economia vulneráveis às inconstâncias do mercado global, as empresas transnacionais se espalharam de um modo acelerado nesse início de século, instituindo polos de consumo e reestruturando o espaço urbano de muitas cidades.

Não se pode pensar em outro sistema de controle maior e mais inexorável - e, nesse sentido, "totalitário" - do que o sistema de capital globalmente dominante, que impõe se critério de viabilidade em tudo, desde as menores unidades de seu "microcosmo" até as maiores empresas transnacionais, desde as mais íntimas relações pessoais até os mais complexos processos de tomada de decisão no âmbito dos monopólios industriais, favorecendo sempre os mais fortes contra o mais fraco (ANTUNES, 2001, p. 25).

Nesse início de século XXI, grandes redes de fast-foods, além de shopping-centers e lojas de departamentos franquiadas, aportaram cidades de porte pequeno e médio, gerando uma reorganização urbana em cidades que, até então, desconheciam essa dinâmica 
metropolitana. É necessário salientar que essas grandes empresas possuem algumas características marcantes: i. Adquirem mercadorias em larga quantidade, sendo possível, então, negociar valores com o fornecedor e repassar a redução do preço ao consumidor, fato que barateia por demais o valor das mercadorias e acirra a concorrência; ii. Em parcerias com operadoras de créditos, essas grandes lojas facilitam o crediário com o cartão próprio, o que gera deslumbre no consumidor pela possibilidade de dividir compras em parcelas a perder de vista, mesmo mediante um endividamento sufocante; iii. O poder financeiro dos mega-empreendimentos permite-lhes investir cifras milionárias em marketing altamente meticuloso e de larga abrangência, de modo a convencer a população sobre qualidade e status embutidos em suas mercadorias; iv. O investimento material também é gigante, fato que ostenta poder dessas grandes empresas na fachada do prédio, na organização de vitrines e na capacidade de arcar com o ônus tributário de espaços urbanos privilegiados (CASTEL, 1998).

Essas especialidades são suficientes para arruinar os micronegócios locais das pequenas e médias cidades, impondo condições insuportáveis para os pequenos investidores. Assim, ocorre um processo de polarização extrema de consumidores e simultânea marginalização dos pequenos proprietários, gerando uma sensação de defasagem das pequenas lojas, agora avaliadas por consumidores capturados pelo deslumbre sutilmente imposto pelo capital internacional.

Nesse contexto, o consumidor local se tornou mais exigente, hoje coagido por trabalho midiático que equaliza o perfil de consumo às tendências globais, obsolescendo cada vez mais as relações de consumo visíveis até século passado, quando o consumidor se adequava à oferta e não o inverso. Agora, a diversidade de mercadorias, o reconhecimento de tendências globais e os trabalhos precisos com a superficialidade imagética são pontos imprescindíveis para sobrevivência no mercado.

Para desenvolvimento da pesquisa no curso do doutorado ${ }^{2}$, tornou-se necessário entrevistar lojistas e ex-lojistas do comércio local em Vitória da Conquista (Bahia). De um modo geral, o que se observou é que os entrevistados não demonstravam grande otimismo com a lucratividade do comércio para os investidores locais. Eis a razão do saudosismo com os anos 1970 e 1980, período em que a concorrência não demonstrava grande ameaça, época também caracterizada pelo ingresso de uma clientela residente em distritos e cidades circunvizinhas sedenta por consumir num comércio hoje concebido como popular e de menor importância.

Por essas razões, as transformações na realidade comercial da cidade nessa virada de séculos não são vistas com bons olhos pelos lojistas entrevistados. Há uma sensação de constrangimento promovido pelos amplos prédios preenchidos pelas lojas de capital externo, fato que marginaliza o comércio local, colocando-o numa posição secundária, incapaz de atrair grandes contingentes de consumidores. Ainda que essas transformações hoje forcem os lojistas a se equalizarem às tendências internacionais, que tem afetado todos os ramos da economia, existe uma subvalorização das pequenas lojas, frequentemente vistas como obsoletas e impossibilitadas de acompanharem a sensação metropolitana adquirida no atual contexto de fusões coorporativas e expansão de megaestabelecimentos comerciais.

Questionamos a todos os entrevistados: "Você me aconselharia iniciar uma atividade comercial hoje?" e a resposta foi categórica para a maioria: "Não". O pessimismo com o comércio conquistense hoje se dá pela elevada carga tributária, pela grave especulação imobiliária que aumentou por demais o preço do aluguel (pago facilmente por grandes lojas de capital externo) e, principalmente, devido à concorrência com megaempreendimentos, que tem arrebatado multidões de consumidores através de um 
meticuloso trabalho de marketing e das imbatíveis condições de venda. Concluem, então, que abrir um novo empreendimento nessas condições se tornou muito arriscado e, por demais, frustrante.

Mais uma vez precisamos salientar que esse pessimismo descrito, bem como as razões para tal, se conecta perfeitamente à dinâmica capitalista vigorante no período ao qual nos referimos. Ora, um governo neoliberal, cimentado por uma carga tributária sufocante para o micro-empresário, favorece o ingresso do capital externo e, consequentemente, corrobora com a concentração de renda que, por efeito, torna as condições de sobrevivência absolutamente desiguais, com o crescimento macrocéfalo de uma economia cada vez mais polarizada e regida pelo gigantismo de poucos. De modo semelhante, a especulação imobiliária apenas contribui para esse processo de exclusão da micro-empresa, pois a lógica é simples e cruel: se há grandes corporações que pagam caro por instalações amplas no comércio, logo, todos os demais devem seguir a tendência de supervalorização imobiliária. A dúbia realidade de expansão e exclusão é, portanto, a máxima do capitalismo nesse início de século XXI.

Nesse cenário de profundas mudanças, a década de 1990 sinalizou para um recrudescimento cada vez maior da desigualdade, com uma exclusão violenta dos investimentos locais e favorecimento extremo dos grandes empreendedores, tudo isso maquiado por uma sensação de prosperidade advinda de um expansionismo concentrador do capital.

\section{Representações e memórias}

Em vésperas do natal, sob os ecos do Black Friday, não por acaso ocorrido na primeira semana de dezembro/2013, a euforia ainda era marcante nas lojas do comércio conquistense. Confetes lançados ao chão, balões com escritos extravagantes afixados no teto, inúmeras TVs de LED reforçando campanhas promocionais da loja, aparelhos de som exageradamente altos, correria de trabalhadores, alto falante congratulando vendedores por metas cumpridas, clientes impacientes, afobação para fisgar o gosto do freguês e muito estresse. Foi neste clima que partimos ao campo empírico, com vistas a entender a forma como comerciantes e comerciários locais visualizam a "nova" realidade econômica da cidade, tendo como base os muitos percursos de vida e memórias implícitas em suas narrativas.

Para operacionalização da pesquisa dentro do campo empírico proposto, realizamos entrevistas $^{3}$ com comerciantes, comerciários, além de aplicarmos questionários trabalhadores do comércio local nos mais distintos ramos e funções (caixas, supervisores, assistentes, vendedores). As idades também foram bastante variáveis, porém foi imediata a constatação de que todos os entrevistados notaram mudanças substanciais na realidade econômica do município nesses últimos anos.

Os comerciários mais jovens (idades entre 18 e 25 anos) chamam atenção para mudanças mais superficiais, como aquelas patentes no espaço geográfico da cidade ou na popularização dos instrumentos de tecnologias; ao passo que os mais velhos (acima dos 30 anos) chamam atenção para transformações nas relações de trabalho e no cotidiano das pessoas, especialmente no que tange às vinculações com os comerciantes e clientes. Assim, o intercruzamento das opiniões, advindas das mais variadas faixas etárias, é imprescindível para entender a forma como se dá a relação entre o mundo de significados e as condições concretas de existência que se desenrolam historicamente. 
Hoje eu acho que essa cidade melhorou demais [...] Eu não conseguiria morar num interior como Conquista era, quando não tinha nada pra fazer (Felipe, comerciário, 19 anos).

Muita coisa melhorou mesmo, mas eu ainda prefiro Conquista um tempo atrás [...] Tinha mais união entre as pessoas [...] Hoje é um querendo passar por cima do outro. (Mauro, comerciário, 38 anos).

Gosto de morar aqui porque temos opções do que fazer no final de semana, também porque no trabalho a gente tem oportunidades que antigamente não existiam (André, comerciário, 22 anos).

Muita coisa melhorou nessa cidade, mas piorou também: engarrafamento, violência, falta de tempo também não é exclusividade de São Paulo (Antônio, comerciário, 37 anos).

Outra diferença também marcante entre os sujeitos de distintas idades é a forma como respondem às mudanças. Confirmando Sennet (2007), os mais velhos são mais resistentes e questionadores sobre as transformações, ao passo que os mais jovens se predispõem facilmente a novos desafios impostos pelos gestores. Um dos entrevistados, Mauro (38 anos), trabalhador de uma grande loja de eletroeletrônico, reconhece que as lojas têm resistência em contratar pessoas que já passaram dos 30 anos e, segundo ele, isso se deve à obsolescência no comportamento dos mais velhos.

Eu já tive amigos me enviando currículo, mas quando passa dos trinta e tantos anos, eu já imagino que vai ser difícil [...] Eu não sei por que, mas acho que a gente vai ficando meio sem forças e também não sabe reagir do jeito que as empresas modernas precisam (Mauro, comerciário, 38 anos).

O comerciário admite que pessoas de mais idade se mostram mais engajadas em lutas por direitos e mostram-se conscientes de leis trabalhistas, ao passo que os mais jovens parecem atribuir seus direitos ao futuro, sentindo-se mais vulneráveis à arbitrariedade imposta pelo emprego atual. Mauro confessa que na década de 1990, quando iniciou suas atividades no comércio, essa realidade também era notória, especialmente porque os mais velhos tinham vivenciado movimentos sociais de décadas anteriores e traziam uma herança de resistência contagiante. Hoje, o entrevistado diz, com pesar, que o conformismo parece ter abocanhado os novos trabalhadores que facilmente se satisfazem com as condições impostas.

Quando o pessoal percebia que o gerente estava pegando pesado, todos reclamavam [...] A insatisfação tinha voz [...] Hoje aqui é cada um por si, brigamos por clientela, competimos nas comissões e todo mundo quer ser o mais bem visto (Mauro).

Outro entrevistado, Júlio, trabalhador do comércio, afirma que direitos trabalhistas como décimo terceiro salário, intervalo para almoço ou salário família, soam como bônus surpreendente para os mais jovens. Esses últimos se sentiriam, segundo o entrevistado, presenteados pelo comerciante com esses direitos, fato que, muitas vezes, retém diversos jovens nesse ramo de trabalho por um longo período, num conformismo com as "bonificações" que buscam escamotear a exploração. 
Essa turma jovem ai pensa que salário é favor de patrão [...] Quando sai o décimo terceiro só faltam agradecer ao gerente [...] Depois que exploram tanto, é pouco o que fazem no final do ano (Júlio, comerciário, 35 anos).

O diretor do sindicato dos comerciários de Vitória da Conquista, atuante na área há vinte anos, informou que hoje encontra grandes dificuldades de mobilizar a categoria, especialmente entre os jovens que compõe parcela considerável dos afiliados. O entrevistado entende que diversas medidas do governo contribuíram para suavizar a sensação de exploração, a exemplo da bolsa família e dos incentivos a estudo no ensino superior privado que, segundo ele, geraram uma sensação de melhora entre a classe trabalhadora. Cabe lembrar o que debatemos no marco teórico acerca da desfiliação generalizada dos trabalhadores com a categoria. Por meio de Castel (1998), Druck (2011) e Harvey (1993), observamos a importância dada pelo capital a elementos subjetivos dos trabalhadores, como o senso de identidade, muito frequentemente afetados por discursos ideológicos que defendem a acumulação inconsequente. Os trabalhadores, evidentemente, não são impermeáveis e imunes a tais articulações discursivas e, tão logo, reproduzem em suas falas os posicionamentos equalizados ao nexo acumulativo do capital.

Antes, quando a gente convocava os sindicalizados era muito mais fácil porque o pessoal se sentia explorado. Hoje com esse consumo, com esses programas de governo que dão dinheiro, com essa campanha de crescimento econômico ai, a turma só procura sindicato quando tem problema grave (Guimarães, sindicalista).

É útil salientar o empenho ideológico dos seguidos governos nas últimas décadas que, apoiados por uma estrutura global de dissolução dos sindicatos, se empenharam na construção ideológica de um conformismo com a sensação tênue de melhorias. A tentativa de injetar na subjetividade dos trabalhadores uma consciência burguesa, apoiada no consumismo, no ideário da empregabilidade e num individualismo extremo foi primordial para o resultado hoje notório: pessoas que entendem o alargamento do poder de consumo como atributo suficiente à classe trabalhadora, hoje mais envolta por reivindicações postas na esfera individual do que na esfera coletiva. Nesse aspecto, a individualização do trabalhador e sua identificação com a lógica acumulativa do burguês representa a triunfo de um projeto de sociedade para Vitória da Conquista, operante dentro de muitas temporalidades e especificidades, mas articulada a intencionalidades típicas de um regime empenhado em garantir a perpetuação do capital.

Não concordo com esse negócio de greve [...] Quem não concorda com o salário que ganha, que saia do emprego. Acho que pessoas procuram desculpa para não trabalhar depois que conquistam o emprego (João, comerciário, 25 anos).

Esse raciocínio coincide com as afirmações de Castel (1998, p. 459), quando menciona que os trabalhadores abdicaram da ação coletiva revolucionária, para deixaremse seduzir "pelas sereias da sociedade de consumo, [...] enquadrada por aparelhos sindicais e políticos reformistas...". Por este motivo, Guimarães, diretor do sindicato de comerciários, afirma que em momentos anteriores a mobilização parecia mais fácil, uma vez que atualmente a consciência de classe trabalhadora recebe ruídos de uma autopercepção aburguesada, ocupada por demais com a realização individual que o consumo e o aparente status social pode oferecer. Em outras palavras, Guimarães 
reconhece que a mobilização sindical parece ter se tornado uma forma antiquada de reivindicação de direitos, soando como antítese do trabalho que, nessa concepção, incondicionalmente honra o cidadão. Essa percepção se agrava entre os trabalhadores mais jovens, que parecem desdenhar da organização sindical, entendida, em grande parte, como elemento prescindível e, portanto, oponente às "novas" atribuições de um trabalhador flexível.

\begin{abstract}
Numa época em que se tinha noção de coletivo, as pessoas ganhavam ruas, lutavam, enfrentavam seus problemas. Hoje movimentos são muito sem sentido [...] Acho que falta de visão coletiva é o que mais me dificulta em movimentar o pessoal [...] Quando me procuram, eu atendo sim, mas noto que os problemas são todos individuais (Guimarães, dirigente sindical).
\end{abstract}

Os próprios trabalhadores, em grande parte, confirmam essa percepção através de seus relatos que reconhecem a importância do sindicado e, inclusive, admitem já terem recorrido em condições atípicas, entretanto essa vinculação sindical ocorre de modo encoberto e não declarado. Parece haver um constrangimento em expor o assunto, uma vez que o sindicalismo não é mencionado como entidade que gere coesão ao senso de pertença daqueles sujeitos à classe, pelo contrário, sindicalizar-se é sinônimo de obrigatoriedade e de precaução mediante questões de ordem judicial e trabalhista. Apesar dos esforços dos líderes em promover eventos como jogos, palestras ou confraternizações, a frequência da maioria dos associados parece forçosa. Felipe, um comerciário entrevistado, entende que sindicalizar-se "é tipo plano de saúde, a gente tem que ter, pois não sabe o futuro".

Sindicato é importante demais [...] A gente sabe que para ser demitido é fácil, mas se isso acontecer comigo eu vou buscar o sindicato para entender meus direitos. É importante ter para prevenção desse tipo de coisa. (Felipe, comerciário, 19 anos).

Concordamos com Alves (2011) quando menciona a captura da subjetividade como parte fundamental do projeto burguês para o capitalismo flexível, capaz de convencer sutilmente que a identidade dos trabalhadores deva ser desprendida daqueles que pertencem à mesma condição, fisgando suas referências aos padrões de consumo e embrutecendo pela individualidade de uma consciência equalizada à priorização ao sucesso pessoal. Não estamos insinuando que a resistência tenha sido extinta, pelo contrário, acreditamos que existem novas formas de burlar o sistema e rebelar contra ele, contudo, a articulação coletiva engajada em causas de classe, essa parece estar apaziguada por uma luta agora individualizada e pontual.

Aqui as pessoas falam que são todos de uma família, mas na realidade é cada um por si. Ninguém é amigo de ninguém na prática [...] Se eu não me cuidar sou passada para trás mesmo. (Alice, comerciária, 28 anos).

Os entrevistados, quando relataram ter recorrido ao sindicato, falam de questões de interesse próprio, nenhum comerciário salientou a coesão da categoria como motivo para o sindicalismo. Márcia, por exemplo, relata que é sindicalizada por uma questão de prevenção apenas, pois em casos de demissão por injusta causa, não recebimento de direitos trabalhistas ou acidentes no trabalho, a comerciária entende que o sindicato, nessas situações, tem papel indispensável. Esses pontos de vistas tomaram uma proporção quase 
epidêmica, pois no momento em que são compartidos, tornam-se convincentes por serem envoltos num sentimento de identidade com o coletivo. Assim sendo, compartilhar corriqueiramente o significado de sindicalizar-se implica em disseminar visões de mundo atreladas ao modelo ideológico presente no espaço de trabalho desses sujeitos. Observemos que a entrevistada não descarta a relevância do sindicato na luta de causas coletivas, mas sequer as menciona.

Sindicato é muito importante [...] Conheci pessoas que já recorreram em casos de acidentes no trabalho e demissão injusta [...] Por isso que ninguém pode ficar desfiliado, senão pode ocorrer o mesmo e não ter como pagar advogado ou lutar por direitos (Márcia, comerciária, 29 anos).

A visão assistencialista sobre o sindicalismo permite interpretar o tom de obrigatoriedade, precaução e formalidade do "ofício" de sindicalizar-se como um ato externo ao sujeito, longe de representá-lo. $\mathrm{O}$ trabalhador não nota o sindicato como parte de si, como membro representativo legítimo de sua categoria, aliás, a própria expressão "categoria" se mostra coesa por demais para denotar a ideia aqui redigida. Quando não individualizado, repartido ou dissipado, o senso de identidade dos trabalhadores mostra-se muito mais próximo da perspectiva burguesa. Assim, a tese do "aburguesamento" criticada por Castel (1998) não ocorre dentro das reais possibilidades de inserção social e salarial dos trabalhadores, mas existe apenas como abstração, cooptando a autopercepção desses sujeitos.

É oportuno lembrar que Halbwachs (2006) entende que a memória funciona a partir de elementos comuns que ligam as pessoas e essas "bases comuns" se situam no "espírito", ou seja, é subjetivação. A partir daí, fica clara a ideia de que o trabalhador não precisa ter condições materiais do burguês para se sentir como tal, de igual modo, ele não precisa notar semelhanças com os membros do sindicato para repudiá-lo. A identificação com certo grupo social ou a rejeição de outros tantos, opera através de ideologias circundantes e não necessariamente do teor homogêneo sugerido por expressões estanques, como "categoria".

Toda arte do orador talvez consista em passar aos que escutam a ilusão de que as convicções e as sensações que neles desperta não lhes foram sugeridas de fora, mas surgiram neles mesmos, que o orador apenas adivinhou o que se criava no segredo de sua consciência e se limitou a emprestar-lhes sua voz. De qualquer maneira, cada grupo social se empenha em manter semelhante persuasão em seus membros (HALBWACHS, 2006, p. 64-65).

O autor aponta uma ideia bastante cabível para se pensar os programas de treinamento nesse contexto de flexibilização. A ideologia circundante nos recentes modelos de gestão faz uso dissimulado de estratégias para adentrar o campo afetivo e emocional dos trabalhadores, arrebatando-lhes o "espírito". A retórica dos treinamentos insiste na subjetividade como matéria-prima de dominação, dissimulando a identidade pela incorporação de interesses burgueses como legítimos a totalidade dos trabalhadores.

Outro fator preponderante, também pontuado pelo diretor do sindicato dos comerciários, tem sido o fascínio que o poder de compra dos trabalhadores tem gerado. A sensação de hoje poder comprar uma motocicleta do ano, bem como adquirir aparelhos de tecnologia de ponta deixa a impressão de que nunca a vida do assalariado foi tão boa. Todos os entrevistados entendem que houve melhorias substanciais nas condições de vida 
da classe trabalhadora nos últimos anos. Alguns comerciários fizeram ressalvas (que serão detalhadas à frente), mas o sentimento de que "finalmente é a vez do 'pobre' poder comprar" é categórica.

Meus pais falavam como a vida era difícil antes [...] Recebiam o salário no final do mês e três dias depois já não dava pra comprar nada direito [...] Eu já tenho meu carro, tenho meu quarto com TV, dvd... Agora finalmente é a vez do pobre também poder comprar. (João, comerciário, 25 anos).

De fato, enche os olhos poder parcelar um carro popular e poder estacioná-lo na frente da loja, atrai a atenção manter um tablet na mochila com acesso a diferentes meios de vinculações sociais, é significativo viajar de avião para Salvador nas férias ou pagar escola particular para os filhos. Essas realizações de compra foram orgulhosamente pontuadas por diversos entrevistados que, unanimemente afirmam que nunca se teve tamanho acesso ao consumo. Muito francamente, como falar em agravamento da realidade social, quando se tem uma sensação geral de acesso ao consumo? Como tratar de pautas de reivindicação, quando o consumo consensualmente parece sintetizar o conceito de qualidade de vida para as pessoas?

A ascensão do poder de compra da classe trabalhadora é parte significativa desse apaziguamento da mobilização, pois, articulando o suposto aumento do poder aquisitivo com a ideologia da empregabilidade - que transfere aos trabalhadores a responsabilidade por construírem-se como cidadãos bem sucedidos - não há mais contra quem lutar e por qual razão lutar.

Um dos questionamentos no qual insistimos foi "Comparando com a realidade que você vivenciou ou ouviu falar, como você entende a realidade atual? Houve melhoras ou pioras?" Nesse momento, os entrevistados acionaram a memória social, invocando posicionamentos suscitados do convívio com o grupo, fato que reforça nossa tese de que as condições concretas de existência moldam as representações comuns e, quando trafegadas pela memória no curso da história, intercruzam "velho" e "novo", passado e presente que se diluem na experiência de vida e no discurso.

Eu trabalho porque preciso conquistar meu espaço na vida [...] Não gosto muito desse emprego aqui não, mas aqui tenho oportunidade de crescer e dar orgulho para meus pais (Lucas, comerciário, 20 anos).

Desde cedo eu sempre trabalhei muito [...] Acho que foi a educação que meus pais me deram e acabei sendo trabalhador como eles sempre foram (Márcia, comerciário, 29 anos).

Não tem coisa melhor do que você comprar suas coisas sem depender de ninguém. Hoje eu sou assim porque sempre reconheci o valor de trabalhar [...] Nunca gostei de ficar em casa sem nada pra fazer [...] Quero fazer carreira e dar orgulho para minha família (André, comerciário, 22 anos).

Embora haja concordância generalizada sobre melhoras nas condições de existência do assalariado do comércio, houve algumas ressalvas quase que imperceptivelmente pontuadas. Sandra (27 anos) observou que existem melhorias sim, porém a concorrência e desunião entre os comerciários hoje parece ter sido acirrada. Felipe (19 anos) salientou que seus pais podiam almoçar em casa e hoje, lamentavelmente, o tempo e a "correria" não lhe permite este "luxo" (palavras do entrevistado). Mauro (38 anos) apontou o conforto proporcionado pela razoável melhoria no poder de consumo, mas notou que antes os 
trabalhadores se ajudavam, alternavam atividades, permitiam rotatividade de funções e suas comissões não os punha numa arena concorrencial tão violenta e desumana. Mauro se referiu aos anos 1990, período em que o processo de deterioração das relações de trabalho já estava dando sinais de que esta seria uma tendência irrevogável, mas essa década ainda continha características tradicionais de vínculos empregatícios minimamente sólidos e relações trabalhistas ainda humanizadas. A avalanche de franquias que aqui aportaram distanciou demasiadamente a relação empregador/empregado, gerando uma impessoalidade que dissolveu o senso de pertencimento do trabalhador em relação ao seu ambiente de trabalho, visto, não como extensão de si mesmo e produto da sua relevância, mas como ambiente hostil, situado numa posição ambígua, ora como mero "ganha-pão", ora como espaço que violenta sua autoestima e aprisiona suas potencialidades.

A memória dos entrevistados participa ativamente da formulação das representações e narrativas, mostrando-se diluída nos argumentos, nas histórias ou situações apresentadas. Tanto comerciantes, como os comerciários recrutaram o passado para substancializar seus argumentos, embora ambos os grupos tivessem posicionamentos diametralmente opostos sobre os questionamentos realizados.

Não precisa nem dizer para você que essa cidade enriqueceu, basta olhar para o passado e comparar agora [...] Tudo hoje é mais fácil, além de termos opções de coisas pra comprar sem necessidade de ir para capital nenhuma (Júlio, comerciário, 35 anos).

A cidade está vivendo outra realidade hoje, mas o problema é que esse comércio ai enriquece rico e empobrece pobre. Agora é a vez dos grandes [...] vocês que são jovens tem de procurar fazer concurso, estudar, porque comércio hoje não banca ninguém mais (Novais, ex-comerciante).

Olha a quantidade de lojas que este centro tem [...] Essa cidade tem dinheiro demais, aqui dá para viver bem se souber como investir. (João, comerciário, 25 anos).

Esse crescimento ai serve para quem já era rico antes [...] $\mathrm{Na}$ minha opinião, o consumidor se tornou exigente demais, desvalorizando seu povo e querendo imitar tudo o que vem de fora. Bom mesmo era quando nada disso ai existia. (Marli Miranda, comerciante).

Os comerciantes tendem a visualizar com negatividade todas as transformações advindas do "novo" capitalismo flexível, especialmente porque redundaram em bancarrota de suas atividades comerciais; ao passo que os comerciários são atingidos por uma euforia inquietante. $\mathrm{O}$ trabalho subjetivo dos novos modelos de gestão, aliado à ascensão do poder de compra desses sujeitos, deixaram a constatação de que hoje é melhor ser classe trabalhadora do que ontem, tanto porque "somos treinados e desafiados", como porque "podemos mais" (expressão empregada por Felipe, comerciário entrevistado de 19 anos).

As posições são múltiplas em função do local onde estes indivíduos desenvolveram suas vidas. As narrativas comparam ontem e hoje dentro de condições concretas que participam das múltiplas trajetórias de vida que fazem dos homens hoje reflexos de uma infinidade de variáveis que aqui não comportaríamos mencionar. As opiniões dos entrevistados carregam interesses ideológicos dos grupos, aos quais todos nós inevitavelmente tendenciamos a realçar nos discursos.

Desse modo, a nossa tese de que a captura da subjetividade imposta pelo "novo" capitalismo flexível, articulado à estrutura neoliberal que se propagou principalmente nos governos dos anos 1990, é verdadeira à medida que as palavras dos entrevistados demonstram anuência com ideário burguês, assentado na individualização do trabalhador e 
enrijecimento da mobilização a partir da sensação de alcance de padrões ideais de consumo. Também constatamos a tese de que a memória se articula à sensação de identidade de distintos grupos (POLLAK, 1992), cujas trajetórias de vida se apegam a condições concretas que, inevitavelmente, participam da formulação dos discursos. A memória é, sim, seletiva por natureza, e como tal está propícia a redesenhos em função de interesses específicos de grupos sociais, logo, por razões óbvias, a memória do trabalhador é distinta da memória do pequeno burguês local. Falar da realidade econômica de ontem e de hoje é, portanto, inscrever opiniões em experiências (vividas ou herdadas) e por realidades materiais totalmente adversas. De todo modo, negligenciar a materialidade da vida que participam da formulação das muitas opiniões, significaria concordar com um idealismo do qual não compartilhamos. As vidas se precipitam numa concretude que monta os cenários e se arquiteta no imaginário das pessoas. Narrar, portanto, é recompor uma memória carregada de emoção, e, sobretudo, apoiada num mundo material.

Lembro que minha avó tinha só uma TV velha para a família toda [...] Hoje eu tenho uma TV de LED no meu quarto e vou comprar outra para meu filho. Isso é melhoria para todos. (Antônio, comerciário, 37 anos).

Minha mãe sempre pegava ônibus para trabalhar [...] Agora eu sempre dou carona, ajudo na feira mensal, temos um carro que deixa tudo mais fácil. (João, comerciário, 25 anos).

Essa loja aqui é popular, mas as coisas que se vende são muito boas. São coisas de luxo com preço barato para o povo. Antes só rico que podia comprar essas coisas todas. (Mateus, comerciário, 23 anos).

Assim, a memória e todo seu poder de reelaboração a partir do presente, como afirma Halbwachs (2006), não é jamais imparcial, mas é moldada e remoldada com cargas fortes de ideologias que lhe atribuem substância. Falar do comércio local de ontem implica em recorrer a ideologias circundantes e narrar pela seleção de episódios, de modo a robustecer o argumento de que "antigamente era melhor" ou "antigamente era pior". Antes de agarrarmos a uma dessas opiniões e nutri-las de argumentos, há que se entender que elas derivam de experiências de vida, elas suscitam da identidade que compõe histórias pessoais intimamente atingidas, seja para melhor ou para pior, pelas transformações globais do capitalismo.

\section{Considerações Finais}

Embora o discurso embutido na base política do capitalismo flexível aponte para uma maior democratização do consumo e consequente melhoria da qualidade de vida geral, na prática esse slogan tem mascarado os efeitos mais perniciosos dos novos paradigmas de acumulação. A permissividade dos governos tem gerado um processo desenfreado de expansão das transnacionais, obrigando micro-empreendimentos a recuarem em seus espaços de atuação, cuja identidade parece estar sendo substituída por uma transnacionalização massificada. O posicionamento saudosista dos comerciantes entrevistados demonstra essa sensação de não mais reconhecimento daquele comércio de outrora, cuja dinâmica parecia tão previsível e amigável. Hoje, para aqueles que insistem no comércio, o cenário se demonstra hostil, trincado por um estrangeirismo cosmopolita, violento em seu poder de persuasão e exclusão.

A realidade antagônica de expansão e exclusão, crescimento e degradação, sofisticação e abandono, parecem coexistir num cenário onde o "novo" e o "velho", o arrojado e o defasado se hostilizam na tentativa de prevalência num contexto de disputa acirrada. A acumulação flexível, como se supunha, agudizou a contradição local, impondo 
uma "permissividade" econômica - base do Estado mínimo - capaz de favorecer os grandes conglomerados transnacionais, cujo crescimento se dá pela polarização do consumo e bancarrota dos micro-empreendimentos, hoje higienizados do novo cenário econômico urbano.

Os comerciantes locais, em grande parte, ainda insistem no negócio que possuem, mas demonstram-se constrangidos por um pessimismo paralisante. Estão cientes de que o novo cenário econômico requer investimentos amplos na faixada do estabelecimento, no marketing da empresa, na redução da margem de lucros para dar conta da concorrência; porém são impelidos pela prudência decorrente de suas limitações econômicas. As taxas de juros embutidas nos empréstimos, além da elevação exorbitante do aluguel, as incertezas com um mercado consumidor cada vez mais fugidio, impedem que os comerciantes almejem ter muito além do que hoje possuem.

A incerteza, imposta pela acumulação flexível, ilustrada pela volatilidade do capital e pelas oscilações constantes do sistema econômico, parece ter chegado a Vitória da Conquista dentro do pacote de mudanças impostas pela transnacionalização da economia. Viver numa cidade de porte mediano, inserida nesse cenário de transformações econômicas dessa virada de séculos, implica em visualizar uma aparente prosperidade, materializada pelo metropolitismo esvaziado de sentido, mas capaz de omitir uma perversa exclusão consentida pelos governos na contemporaneidade.

É nessa condição que a memória dos lojistas perpassa por um saudosismo acerca de outro cenário, desenhado por condições concretas muito distintas das que hoje percebemos e muito mais propícias à sobrevivência e criação de perspectivas. Dessa forma, os anos 1970 e 1980 são apontados, em outros termos, como épocas cujos sonhos ainda subsistiam, cujas possibilidades ainda eram cogitadas. Quando historiadores definem a década de 1980 como "década perdida", cabe ponderar que este slogan possui posicionamentos ideológicos que falseiam a totalidade implícita na dinâmica capitalista: "Perdida para quem?". Os índices de crescimento econômico hoje divulgados devem ser, portanto, relativizados, pois precisam considerar o caráter concentrador dos novos paradigmas de sobrevivência do capital.

$\mathrm{Na}$ outra ponta de análise, encontram-se os trabalhadores, cujas opiniões, articuladas às experiências pessoais de vida, leem as mudanças como parte de possibilidades de projeção social. $\mathrm{O}$ aumento no poder de consumo, atrelado à magnitude das mudanças espaciais da cidade, interpenetram a subjetividade dos sujeitos, gerando uma consensual ideia de que "estamos no caminho certo". De todo modo, mais importante do que deflagrar a veracidade dessas opiniões, é mais cabível compreender que a experiência corrobora decisivamente na construção de significados, especialmente porque falar de subjetividade requer considerar a concretude da existência por onde ela se esboça.

Referências:

ALVES, G. Trabalho e subjetividade: o espírito do toyotismo na era do capitalismo manipulatório. São Paulo: Boitempo, 2011.

ANTUNES, R. O sistema do metabolismo social do capital e seu sistema de mediações. In: (org.). Os sentidos do trabalho. São Paulo: Biotempo, 2001.

BARBOSA, A. M. S. O empreendedor de si mesmo e a flexibilização no mundo do trabalho. Revista de Sociologia e Política. Vol. 19, Num. 38. Curitiba, 2011. Disponível em: http://www.scielo.br/pdf/rsocp/v19n38/v19n38a08.pdf . Acesso em 10 de maio de 2013. 
BRAGA, R. A vingança de braverman: o infotaylorismo como contratempo. In: ANTUNES, R. \& BRAGA, R. Infoproletários: degradação real do trabalho virtual. São Paulo: Boitempo, 2009.

CASTEL, R. As metamorfoses da questão social: uma crônica do salário. Trad. Iraci Poleti. Petrópolis: Vozes, 1998.

DRUCK, G. Trabalho, precarização e resistências: novos e velhos desafios? Caderno CRH, Salvador, vol. 24, num. 01, 2011. p. 70-89. Disponível em: http://www.scielo.br/pdf/ccrh /v24nspe1/a04v24nspe1.pdf Acesso em: 27 de setembro de 2013.

HALBWACHS, M. A memória coletiva. Trad. Beatriz Sidou. 2. ed. São Paulo: Centauro, 2006.

HARVEY, D. Condição pós-moderna. Trad. Adail Sobral. São Paulo: Loyola, 1993.

KOSIK, K. Dialética do concreto. 2. ed. Trad. Célia Neves e Alderico Toríbio. São Paulo: Paz e Terra, 2010.

PINTO, G. A. A organização do trabalho no século 20: taylorismo, fordismo e toyotismo. 2.ed. São Paulo: Expressão Popular, 2010.

SENNET, R. A corrosão do caráter: as consequências pessoais do trabalho no novo capitalismo. 2. ed. Trad. Marcos Santarita. Rio de Janeiro: Record, 2009.

A cultura do novo capitalismo. Trad. Clovis Marques. 3. ed. Rio de Janeiro: Record, 2007.

\footnotetext{
${ }^{1}$ Doutor em "Memória: Linguagem e Sociedade" pela Universidade Estadual do Sudoeste da Bahia - UESB; professor adjunto do Centro de Cultura, Linguagens e Tecnologias Aplicadas - CECULT da Universidade Federal do Recôncavo da Bahia - UFRB

${ }^{2}$ Desenvolvemos tese intitulada "Memória do trabalhador no contexto da acumulação flexível", em que partimos do comércio varejista do município de Vitória da Conquista - BA, para compreender os efeitos da acumulação flexível nos diferentes espaços urbanos.

${ }^{3}$ Os sujeitos de pesquisa tiveram suas identidades omitidas, sendo aqui apresentados nomes fictícios.
}

Recebido: $\quad$ setembro-13 Aprovado: setembro-14 